\title{
Sobre os monumentos escultóricos: por uma pedagogia da memória
}

\author{
Alex Medeiros Kornalewski
}

Sobre os monumentos escultóricos: por uma pedagogia da memória

Resumo: A presente pesquisa tem por objetivo refletir sobre os suportes escultóricos que adquirem a qualidade de monumento, além de refletir sobre a sua função pedagógica. Sendo assim, alguns apontamentos sobre a relação conceitual entre memória e história mostram-se fundamentais para pensar sobre os monumentos. Em complemento, discute-se a distinção entre monumento e monumento histórico. Em seguida, discorre-se sobre a função pedagógica dos monumentos, tomando como exemplo ilustrativo o Monumento Nacional aos Mortos da Segunda Guerra Mundial (monumento aos pracinhas) localizado no Aterro do Flamengo, Rio de Janeiro e o monumento fúnebre de Ary Barroso localizado no cemitério São João Batista de Botafogo, Rio de Janeiro. Por fim, apresenta-se uma proposta interdisciplinar ao incluir os monumentos na prática pedagógica, ressaltando a existência de vantagens e desafios que os seguintes atores - aluno, professor e bibliotecário - podem se deparar, além de considerar o último essencial no processo educacional proposto.

Palavras-Chave: Memória. Educação. Monumento. Bibliotecário.

Effective About the sculptural monuments: by a pedagogy of memory

Abstract: This research aims to reflect on the sculptural holders who acquire the monument quality, and reflect on their pedagogical function. Thus, some notes on the conceptual relationship between memory and history show is fundamental to think about the monuments. In addition, it discusses the distinction between monument and historical monument. Then it talks about the pedagogical function of the monuments, taking as example the National Monument to the Dead of the Second World War (monument to 'pracinhas') located in Flamengo, Rio de Janeiro and the funerary monument of Ary Barroso located in the cemetery São. João Batista in Botafogo, Rio de Janeiro. Finally, we present an interdisciplinary approach to include monuments in teaching practice, noting the existence of advantages and challenges that these actors - student, teacher and librarian - may face in addition to considering the last essential in the proposed educational process.

Key-Words: Memory. Education. Monument. Librarian.

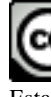

Esta obra foi licenciada sob uma Licença Creative Commons - Atribuição 3.0 Não Adaptada. 


\section{Introdução}

As relação tênue e de inúmeros conflitos entre a memória e a história nos direciona para uma constante politica, entre o que se deve lembrar e o que é alçado ao território obscuro do esquecimento. No limiar desse embate, certas escolhas são elevadas e eleitas como um registro rígido e social do que deve ser aceito como verdade, em outras palavras, tomam o status de história. Em complemento, temos o sujeito que exerce a função do educador que, por intermédio de sua experiência e das ferramentas que lhes são apresentadas, age como um catalisador, a fornecer-nos o embasamento cultural que carregamos e modificamos ao longo de nossas vidas.

Pensando nas fontes informacionais à disposição do educador, podemos citar uma miríade de suportes disponíveis para fins pedagógicos: fotografias, livros, mapas, áudio, filmes, esculturas, sites. Porém, pretende-se refletir sobre uma particularidade, passível de ser legitimada nas fontes de pesquisa, e que estabelece uma relação singular com as questões pertinentes ao campo da memória: é a qualificação de um suporte como monumento, ou o status de um suporte monumental. Assim sendo, considera-se fundamental o entendimento sobre o conceito de monumento e suas implicações, utilizando-se de autores como Le Goff (2012), Choay (2006), Riegl (2014) e Assmann (2011).

Após essa explanação sobre a questão do monumento e como os suportes adquirem valor ou status de monumental, ou mesmo qualificam-se como monumentos históricos, segundo as escolhas do pesquisador, cabe-nos pensar sobre às possibilidades pedagógicas deste suporte mnêmico. Para tal, o presente trabalho traz dois monumentos escultóricos, distintos em sua composição representativa, nas memórias e locais onde foram edificados: o monumento fúnebre de Ary Barroso, localizado no Cemitério de São João Batista de Botafogo, no Rio de Janeiro e o Monumento Nacional aos Mortos da Segunda Guerra Mundial (monumento aos pracinhas), localizado no Aterro do Flamengo, também no Rio de Janeiro.

Além das diferenças entre os monumentos selecionados, foi considerado seu teor ilustrativo para a pesquisa, de forma a ressaltar as vantagens e desvantagens em se utilizar de um suporte que permite a interdisciplinaridade, entre o educador e o educado, além de nos permitir incorporar o bibliotecário neste cenário, uma vez que sua atuação como médium, entre os suportes ditos monumentais utilizados em pesquisa e o corpo social segmentado pelos alunos, professores e o próprio bibliotecário, fomenta $\mathrm{o}$ desenvolvimento do ambiente pedagógico, no sentido de construção de conhecimentos e competência informacional (DUDZIAK, 2003) dos próprios atores citados.

\section{Pedagogia da memória: lembrar para aprender, lembrar para ensinar}

A memória é polissêmica (GONDAR, 2005), e como tal permite-nos inúmeras interpretações e apropriações de acordo com as necessidades de determinada área do conhecimento. Todavia, podemos iniciar a discussão sobre a memória por seus viés psicológico, que segundo Le Goff (2012, p. 405) nos remete a "um conjunto de funções psíquicas, graças às quais o homem pode atualizar impressões ou informações passadas, ou que ele representa como passadas". Pelo psiquismo, o homem pode apreender, de acordo com a sua visão de mundo, e moldar essa percepção da forma como lhe convém. 
Logo, entende-se que a memória atua no presente, tomando como fonte o outrora, se constituindo por intermédio de processos conflitantes entre lembranças e esquecimentos, que por sua vez resulta em escolhas do que se considera descartável e do que se deseja perpetuar. A memória, como uma preocupação de ordem social, nos permite observar que da mesma forma em que temos a transmissão de narrativas para as gerações vindouras, também temos aquilo que é silenciado, esquecido, revelando a existência de mecanismos de manipulação da memória (LE GOFF, 2012, p. 408).

Esse processo de construção da memória torna-se mais claro quando entendemos que "toda memória pode ser considerada uma narrativa de algo" (RIBEIRO; OLIVEIRA; WILKE, 2010 p. 167). Logo, se a memória narra alguma coisa, então também temos o narrador, ou seja, aquele - indivíduo, grupo, sociedade e afins - que almeja a perpetuação e o intercambiar de experiências (BENJAMIN, 2012), podendo ocorrer de forma voluntária ou involuntária, o que demonstra a existência de uma dimensão política da memória (LE GOFF, 2012; MORAES, 2005).

Para além desse processo de escolha, ou político, em que a memória se constitui, temos outro viés no qual Pires $(2012$, p. 8) apresenta a narrativa como uma "articulação histórica para conhecer o passado [que] não está no fato do registro, mas na apropriação da reminiscência, que se funda na tradição e se vincula à transmissão de conhecimentos ou de experiências". Em síntese, podemos dizer que tanto a memória quanto a história apresentam em seu processo, ou como meio, a narrativa, a experiência, sendo que na memória temos essencialmente o interesse de perpetuar algo, enquanto que na história temos uma apropriação de algo com fins instrutivos, documentais, sendo portanto uma escolha do historiador ou pesquisador (LE GOFF, 2012).

Todavia, Pierre Nora em seu artigo Entre memória e história: a problemática dos lugares (1993), acrescenta algumas problematizações nesta relação entre a memória e história. Para ele a memória evoca o passado, porém é um processo que se dá no presente, abrindo constantes diálogos entre a lembrança e o esquecimento. Porém, ele observa que a história é sempre uma construção problemática e incompleta sobre algo que não mais existe (NORA, 1993). Logo, percebe-se que o uso das fontes para pesquisas ou fins pedagógicos implicam numa necessidade clínica de se considerar as questões políticas que edificaram a memória sobre as fontes que se quer utilizar, bem como dos registros propriamente ditos, escolhidos à luz da história.

Se apresentamos essa relação entre a memória e a história, cabe-nos fazer alguns apontamentos sobre a função pedagógica, e como esta lida com este campo da memória e sua historicização. Pedagogia, é uma palavra de origem grega paidos (criança) + gogía (conduzir, acompanhar), e refere-se aos escravos que levavam as crianças às escolas. Atualmente, o termo caracteriza o processo de instruir, ensinar, educar (MICHAELIS, 2014). Portanto, na função pedagógica, temos a junção de aspectos pertinentes a memória e a história, tais como: o ato de instruir as civilizações sobre os feitos memoráveis de seus reis, educar perante a normalização de experiências que por sua vez edificam costumes - e aqui temos o uso da memória ao narrar estas experiências e a solidificação das mesmas por intermédio de práticas e documentos - além de legitimar determinadas memórias, em termos etimológicos, como um fator de prova e de ensino (LE GOFF, 2012).

Alves (2012, p. 208) enfatiza: "a relação com o passado é um âmbito fundamental da ação educadora". O uso pedagógico que o educador faz da memória lhe 
concede subsídios, ao fortificar seu discurso no ensino por intermédio da dinamicidade e flexibilidade da memória para, com base nas experiências de si de outrora, rever no presente o que será perpetuado para outras gerações. Avigoro que esta transmissão é dotada de uma intencionalidade, mesmo que involuntária, do sujeito que exerce esta função de educador e transmissor de experiências. Por vezes, esta dinamização da memória entre o que a detém (sujeito, classe, pesquisador, educador) e o que a ingere para finalidades futuras (filhos, alunos, gerações e afins), contribuem para a construção e consolidação do "sentimento de identidade, tanto individual como coletiva" (POLLAK, 1992, p. 204).

Sobre o conceito de identidade, Huyssen $(2004$, p. 67) reforça que a memória nos permite "construir e ancorar nossas identidades e alimentar uma visão do futuro". Podemos depreender que a memória é um importante viés com vistas à informação, pois é deste néctar mnemônico que tiramos proveito do que foi evocado no presente para constituir nossa identidade e propiciar ações para o futuro, o que nos faz pensar neste ato mnemônico como um processo pedagógico atemporal. Diante desta pedagogia da memória, vale elencar um importante suporte mnêmico que possibilita o exercício desta função de instrução, educação e ensino: os monumentos, especificamente os de cunho escultóricos, como as esculturas públicas alocadas no centro das cidades, cemitérios e demais lugares.

\section{Monumento ou monumento histórico?}

A palavra latina monumentum origina-se do verbo monere que significa "fazer recordar", palavra que abriga em sua origem os valores arquétipos da musa Mnemosÿne, divindade mencionada como a personificação da memória. A noção de monumento é ampla, e abriga mais do que suas especializações físicas, como as obras comemorativas e os monumentos fúnebres, qualificações empregadas em arquiteturas, esculturas e túmulos desde a antiguidade romana. O termo monumento se aplica a inúmeros campos: pessoas, textos, músicas, língua, enfim, o caráter de monumento se aplica de acordo com os interesses de perpetuação daqueles que o elaboram, bem como das relações de poder que interagem na formação e constituição do monumento (LE GOFF, 2012).

Em 1904, um historiador de arte, o vienense Alois Riegl, já dissertava sobre a importância dos monumentos na modernidade, e em comparação com outros monumentos históricos, na obra intitulada "O culto moderno dos monumentos". Para Riegl (2014, p. 31) os monumentos são criações "do homem e elaborada com o objetivo determinante de manter sempre presente na consciência das gerações futuras algumas ações humanas ou destinos (ou a combinação de ambos)".

Em complemento, entende-se que os monumentos se distinguem em dois aspectos: os de cunho comemorativo, por exemplo, os monumentos de datas importantes, homenagens, evocações nacionalistas e os de cunho fúnebre, como é o caso dos mausoléus, túmulos e cenotáfios (LE GOFF, 2012). Aleida Assmann em seu livro Espaços da recordação (2011), propõem esta segmentação conceitual dos monumentos sob a seguinte ótica: a primeira é a dimensão do sagrado, ou pietas, no qual temos a preponderância das religiões e a dimensão mundana ou fama, em que a 
memoração impera em questões como: indivíduo, grupo, classe e afins, sendo que essa "fama ou "memoração cheia de glórias", cada um pode conquistar para si mesmo, em certa medida, no tempo de sua própria vida" (ASSMANN, 2011, p. 37).

Sobre o conceito de monumento, podemos considerar três características: primeiro, há uma pluralidade de suportes materiais e imateriais que podem ser eleitos à categoria de monumentos; segundo, a construção de um monumento ou eleição de uma obra á categoria do monumental implica numa escolha política e, por último, os monumentos refletem questões da ordem do imaterial (sagrado, emoções e afins) e material (feitos memoráveis, informação sobre a pessoa ou uma instituição).

Além disso, os monumentos são uma fonte informacional em formato tridimensional e incrustado de símbolos icônicos, o que permite-nos enveredar por inúmeras discussões, memórias, e interferências, que fizeram parte do processo de construção deste suporte mnemônico, por exemplo: recordações de familiares, históricas, religiosas, de instituições militares entre outros que muitas das vezes podem coabitar o mesmo monumento escultórico. Entende-se que os monumentos são engenhosos, e podem englobar um vasto campo de memórias num único suporte escultórico, ou, apropriando-se das palavras de Dodebei (2008, p.19), é: "muito mais criativo do que objetivo, [pois] o espaço/tempo imagético é habitado-vivenciado por uma memória social dinâmica e interativa, experimentada em tempo real".

Se considerarmos o sentido etimológico da palavra monumento, depreende-se que esta segmentação proposta por Le Goff e depois revista por Assmann é meramente didática. A própria construção ou mesmo o simples interesse de erigir um monumento já envolve um discurso fúnebre, de perda, uma vez que o monumento ou os processos de monumentalização se destinam principalmente em manter presente, perpetuar a memória daquilo que padeceu, mesmo que de forma simbólica. Em resumo, os monumentos podem discorrer sobre a morte de forma explícita (monumentos fúnebres) ou implícita (comemorações e afins), tendo como prática discursiva a retórica da perda, empregada para "salvaguardar" a memória e a identidade (GONÇALVES, 2002).

Outro questão pertinente é a distinção entre monumentos e monumentos históricos. O monumento tem por finalidade o reviver de um passado, enquanto que os monumentos históricos são a apropriação que fazemos dele, tornando-os objetos de saber (CHOAY, 2006). Destarte, os monumentos históricos podem ser considerados aqueles escolhidos pelo historiador, pesquisador, ou seja, são os monumentos que além de perpetuarem memórias são também utilizados para fins específicos daqueles que os elegeram. Esta qualificação dada aos monumentos retoma suas primeiras finalidades, que para Choay (2006, p. 26) implica no: "valor cognitivo sobre o passado, história geral ou a história da arte em particular".

Portanto, é crível afirmar que os monumentos possuem uma amplitude de memórias que podem ser apropriadas por aqueles que delas necessitam, seja um indivíduo, grupo ou sociedade. Da mesma forma, a intenção com que escolhemos determinados monumentos para realçar e construir as memórias e a identidade de um determinado grupo podem imbuir o status de um monumento a dimensão histórica. Sendo assim, as memórias dispersas nos monumentos e os monumentos históricos, eleitos assim por determinadas necessidades da sociedade, são meios singulares de compreendermo-nos no presente além de nos fornecer informação para lidar com o porvir, tal como Huyssen (2004, p. 67) ressalta. 
Alves (2012, p. 209) reforça que: "da mesma forma como prédios, monumentos, documentos sobrevivem e permanecem guardados por longos períodos, também concepções, práticas, valores, preconceitos atravessam os tempos e se manifestam no presente, parecendo por vezes intactos". Tomando esta citação como início investigativo do uso pedagógico dos monumentos, é mister levantarmos algumas questões: como pesquisador, educador ou mesmo alunos podem se portar quanto ao uso dos monumentos no currículo disciplinar? Como aproveitar os monumentos para despertar um olhar crítico e reflexivo sobre as diversas memórias que nos cercam e a história que delas se apropria?

\section{Sobre o uso pedagógico dos monumentos: práticas e desafios}

Independente do formato, compreende-se que os monumentos são suportes de memórias no plural da palavra. As músicas, esculturas, arquiteturas e afins fomentam um turbilhão de memórias sobre quem fez a obra, para quem foi feito, e como a sociedade enxerga determinada construção, o que reforça a riqueza destes instrumentos que podem nos auxiliar a entender um pouco do nosso passado, da nossa história, além de propiciar reflexões por parte dos usuários que deles utilizam: alunos, professores ou pesquisadores em geral. Para ilustrar esta característica pedagógica dos monumentos, podemos exemplificar com o monumento dedicado aos mortos da Segunda Guerra Mundial ou Monumento aos Pracinhas como eram chamados os soldados que lutaram nos campos da Europa.

O monumento abaixo (fig. 1), representa os soldados mortos na Segunda Guerra Mundial, homenageando-os como patriotas que serviram ao país nos campos de guerra. Em aditamento, inúmeros signos são apresentados nos monumentos: tem-se a escultura de um grupo composto por três soldados que representam os três podres militares; uma escultura metálica que representa a engenharia aérea militar; uma pirâmide triangular com informações sobre inauguração, comissão e equipe responsável pelo projeto; embaixo do pórtico monumental há uma urna representando a memória do soldado desconhecido e para finalizar embaixo da plataforma monumental foi construído um mausoléu com 466 militares mortos na Campanha da Itália (MONUMENTO NACIONAL AOS MORTOS DA SEGUNDA GUERRA MUNDIAL, 2014). 


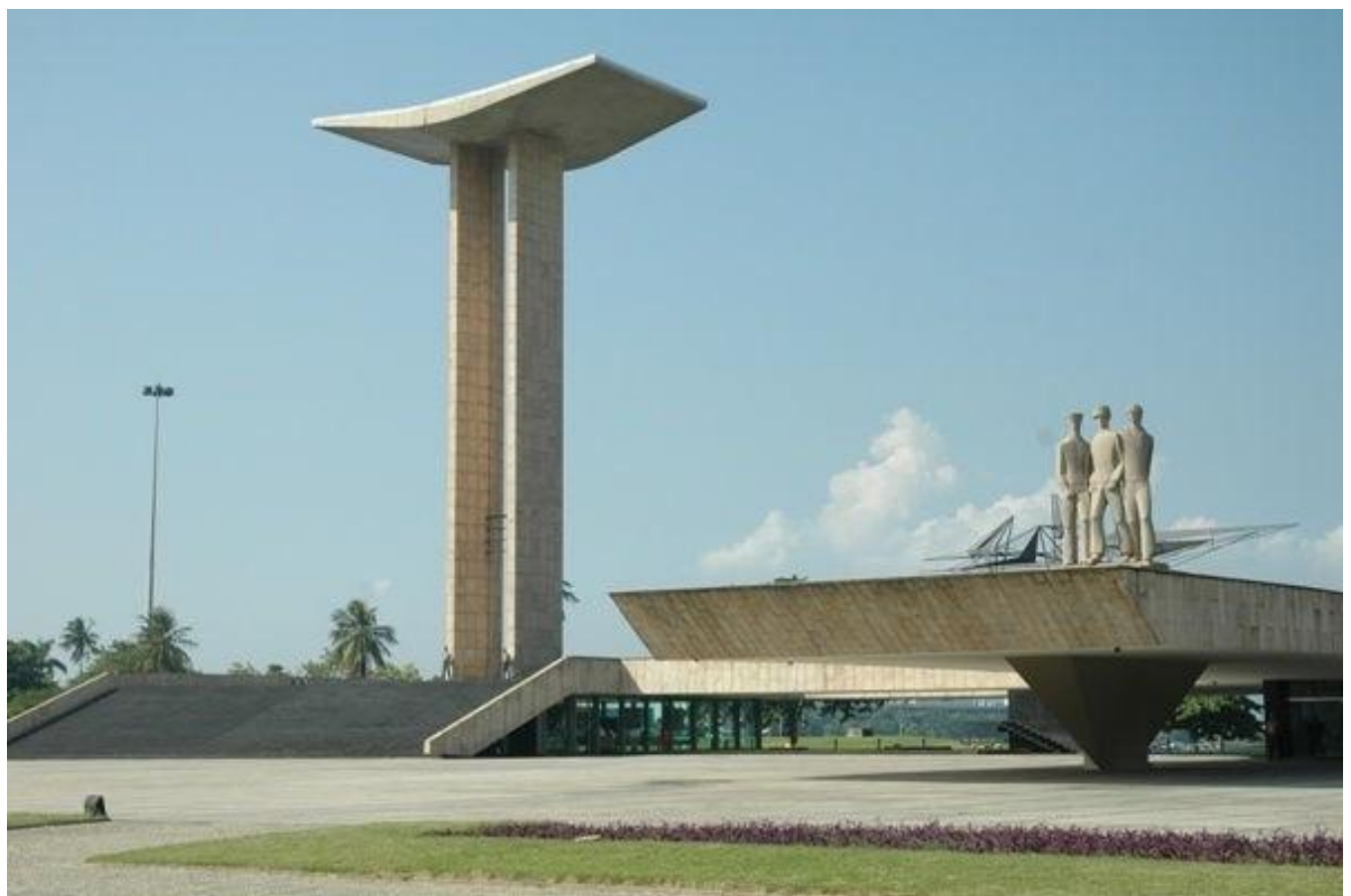

Figura 1 - Monumento Nacional aos Mortos da Segunda Guerra Mundial.

Fonte: http://www.museusdorio.com.br. Acesso em: 19/04/2014

Para além da concepção de suporte de memórias, o monumento em questão foi construído com base nas escolhas políticas de um corpo militar, representando um evento que envolve o país, os soldados (seja os mortos ou os sobreviventes), suas famílias (ator indireto do evento, porém carregado de memórias sobre o mesmo), a instituição militar (Marinha, Exército e Aeronáutica), o Estado. Diante desta função mnésica dos monumentos, podemos atribuir sua segunda função: a pedagógica.

O educador pode utilizar-se dos monumentos nas pesquisas escolares de forma a instruir, ensinar, educar e, por conseguinte, estimular o processo reflexivo dos alunos, motivando pesquisas de cunho histórico, político, sociológico, psicológico em diante. $\mathrm{O}$ uso pedagógico dos monumentos em consonância com o processo de "escavar a memória", para entendermos o presente e adquirirmos uma visão crível do futuro, nos permite uma expertise singular e dinâmica quanto às memórias e o registro histórico representado na iconografia dos monumentos, o que realça a qualidade pedagógica do mesmo além de legitimar seu status de prova histórica, constituindo-se como um monumento-documento (LE GOFF, 2012). 


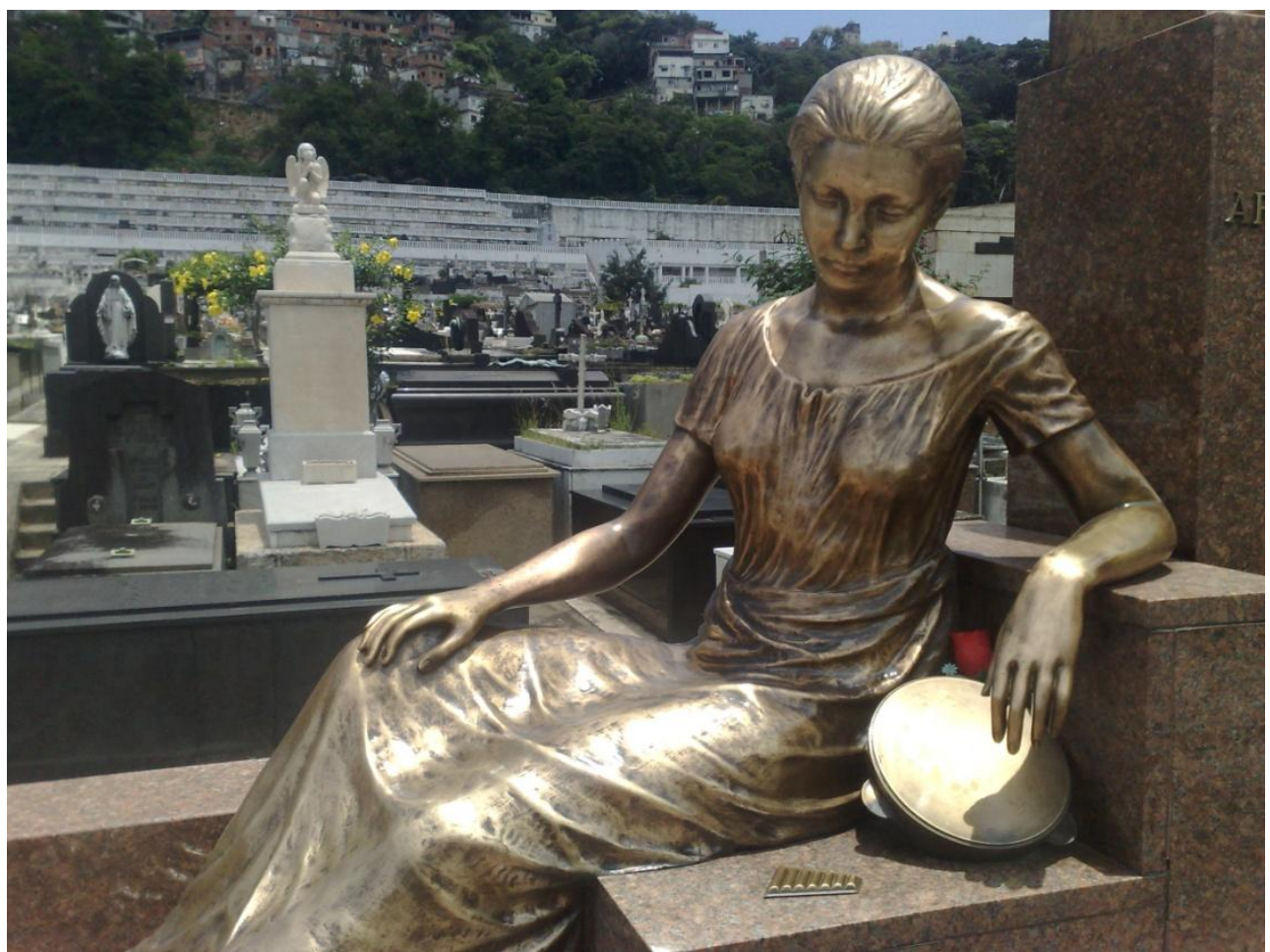

Figura 2 - Monumento de Ary Barroso.

Fonte: Acervo pessoal do autor, 2014.

Outro monumento de visível riqueza mnemônica e informativa é o monumento dedicado ao compositor Ary Barroso (fig. 2). Nasceu em 7 de Novembro de 1903 em Ubá, Minas Gerais e faleceu em 9 de Fevereiro de 1964 no Rio de Janeiro. Compositor, pianista, locutor, apresentador, formado em direito, iniciou suas atividades musicais aos 12 anos de idade, fazendo fundo musical para filmes no Cinema Ideal. Entrou na política em 1946, como o segundo candidato mais votado da União Democrática Nacional (UDN) nas eleições para a Câmara de Vereadores do Rio de Janeiro. Na política, teve grande voz possibilitando a construção do estádio do Maracanã. Compôs e participou de mais de 260 músicas dentre as quais podemos citar a popular "Aquarela do Brasil"' (ARYBARROSO.COM.BR, 2014).

O monumento acima retrata a relação de Ary Barroso com a música, conforme vemos nos símbolos icônicos e textuais do suporte: o pandeiro, nome de algumas composições. Se tomarmos o monumento como base inicial das pesquisas, pode-se depreender que as memórias de Ary Barroso contemplam o samba, sua relação sentimental com a música e com a identidade musical brasileira. Diante dessas "memórias superficiais" ou de fácil rememoração que obtemos ao perscrutar o monumento fúnebre do compositor, temos um campo extenso de estudo no qual o compositor, a música e a cultura brasileira podem nos levar a outros campos de estudo e atuação daquele que em vida teve ampla participação em outros setores dentre os quais o cinema e a política. $O$ uso pedagógico dos monumentos pode nos levar além do que suas composições físicas representam, incitando-nos a olhar o mesmo suporte por outras perspectivas.

Diante dos monumentos exemplificados, podemos depreender as seguintes características: são monumentos que se constituem num suporte tridimensional, em sua composição há inúmeros símbolos icônicos e constroem uma memória social isenta de 
inocuidade, pois estes monumentos resultam de uma montagem daqueles que os produziram, que impuseram determinadas lembranças em detrimento de outras que foram forçadas ao esquecimento, além das imposições sociais no qual estes monumentos continuam a existir (GONDAR, 2005, p. 17). Assim, todo monumento construído remete a determinadas intenções políticas do que deve ser evocado com o intuito de ser rememorado ou registrado pela história.

Esta 'micropolítica' existente na constituição dos monumentos e das memórias que podemos analisar nestes suportes, nos remete a uma dupla conceitual que se relacionam constantemente: o conceito de memória vicária e subterrânea. Sarlo em seu livro Tempo passado: cultura da memória e guinada subjetiva (2007), evoca algumas definições sobre este caráter vicário da memória, no qual ela designa a palavra vicária como, aquilo que lembramos sem contudo ter vivenciado (YOUNG, 2002), além de considerar este processo como pós-memória (HIRSCH, 2012). Para a autora, a memória vicária é um processo de substituição intencional com o intuito de tornar visível determinadas lembranças em detrimento de outras que se deseja soterrar (SARLO, 2007).

Quanto ao conceito de memória subterrânea, entende-se como aquilo que se encontra sobrepujado, em sua maioria pelas memórias ditas "oficiais", à espera de um possível ressurgimento, no qual podem ser desveladas, pesquisadas, evidenciando-se para a sociedade (POLLAK, 1989).

Este par conceitual, memória vicária e memória subterrânea, permite que os atores envolvidos com o uso pedagógico dos monumentos escultóricos, desenvolvam uma visão crítica dos mesmos, adquirindo um olhar que lhes permite observar camadas mais ocultadas do que o visivelmente representado. As possibilidades de pesquisa e apropriação das narrativas para fins informacionais - uso por parte de alunos, didática do educador, pesquisas de um público em geral - tornam-se mais abrangentes e dinâmicas, gerando um valor agregado a informação já disponível para os usuários ou mesmo lhes fornecendo informação fundamental, que segundo Le Goff (2012, p. 510): "só numa parcela mínima são testemunhos escritos", ou seja, disponíveis em formato impresso.

Entende-se que a gênese da informação se dá, segundo Varela (2007, p. 44) no "esforço humano de entender e interpretar a realidade, de comunicar a imagem que cada indivíduo faz do seu meio, que a informação é gerada", dito de outra forma, depende da nossa capacidade de interpretar a realidade, a imagem - neste caso exemplificado pelos monumentos - para que a informação seja gerada, disseminada, o que denota uma construção social (VARELA, 2007).

Outrossim, para que aja uma utilização pedagógica dos monumentos, é mister que os atores (pesquisador, alunos, professores e afins) desenvolvam constantes diálogos sobre o que se pretende trabalhar, demonstrando clareza didática por parte do uso que pretende ser feito ao colocar os monumentos como meio educativo, somado com uma proposta crítica-reflexiva, por exemplo, problematizando-as para alunos e demais receptores que possam usufruir dos monumentos, ao invés de considerá-los apenas como ilustrações de um determinado tema a ser abordado em sala de aula (MOURA, 2011). Essa clareza e envolvimento entre o professor e o aluno, é uma proposta que tem como mote a dificuldade de estabelecermos uma metodologia de ensino interdisciplinar tal como (SILVA, 2011) relata em suas experiências. 
Quanto aos docentes, uma proposta interdisciplinar, e neste caso utilizando-se de um recurso interdisciplinar como os monumentos, para desenvolver um trabalho com os alunos, pode acarretar numa incompreensão de como proceder com o ensino, dificuldade esta que é uma marca "positivista ou conservadora da ciência" (SILVA, 2011, p. 588). Dito de outra forma, uma metodologia que se apropria dos monumentos para fins pedagógicos, implica em dificuldades devido aos múltiplos vieses que se podem desenvolver sobre os mesmos: o viés histórico, político, geográfico, psicológico, sociológico.

Quanto aos discentes, as possibilidades aplicadas pelos professores, mesmo quando injetam motivação nos alunos que enveredam em estudos e criam pesquisas mais dinâmicas, podem provocar estranhamento e resistência nos próprios alunos, uma vez que a ausência de clareza na proposta das disciplinas e a dificuldade de se utilizar recursos considerados polissêmicos e interdisciplinares, como os monumentos escultóricos apresentados, fotografias e demais suportes, impõem uma complexidade singular se comparado com os métodos tradicionais de ensino (SILVA, 2011).

Essa dificuldade de utilizar ferramentas visuais e ou em formato tridimensional em salas de aula, ocorre em parte, pelo fato desse tipo de recurso não ser tratado "como objeto de estudo que deve ser priorizado, do ponto de vista metodológico, nas ciências sociais" (MOURA, 2011, p. 162). Logo, temos uma dificuldade que atinge ambos os lados, contribuindo para o bloqueio de novos métodos pedagógicos, que tenham o foco na interdisciplinaridade, 'engessando' a aula tanto no conteúdo quanto no método adotado de ensino, o que por sua vez implica num "empobrecimento de um conhecimento histórico do processo educativo (enquanto processo formativo)" tal como Pires (2014 p. 15) enfatiza.

Assim, é importante que mais do que informar ou apreender, deve-se considerar o próprio processo que consolidou aquela informação, as narrativas que permeiam o assunto a ser discutido entre o professor e aluno, em síntese, deve ocorrer um intercambio de experiências (BENJAMIN, 2012), o que permite a dinamização dos recursos a serem utilizados, tal como o exemplificado com os monumentos escultóricos, promovendo o encorajamento do processor a sair da sua zona de conforto, além de corroborar com a clareza do que se pretende dos alunos ao aplicar tal método pedagógico, que objetiva a interdisciplinaridade quanto aos recursos utilizados e quanto ao método de ensino.

Percebe-se que o diálogo entre docente, discente ou pesquisador, orientador, enfim esta relação de aprendizado requer uma atenção em como e o que será usado de forma pedagógica, sejam monumentos escultóricos, livros, músicas entre outros. Para tal, vale inserirmos um ator, que pode acrescentar nesta relação de aprendizagem: o bibliotecário. O mesmo possui em seu cotidiano profissional, a experiência com acervos compostos por inúmeros suportes ou pesquisas complexas que envolvam informação que muitas das vezes não e encontram no próprio ambiente de trabalho, seja na biblioteca, escola e demais instituições.

Com isso, acredita-se que o bibliotecário pode contribuir diretamente nesta relação de aprendizagem, além de auxiliar o educador com o desenvolvimento de um roteiro, necessário para um método pedagógico que tem por base a memória (ALVES, 2012). Além disso, o bibliotecário acrescenta, com sua expertise em fontes de informação, ampliando o acesso e indicando fontes desconhecidas ou de pouco uso por 
parte dos alunos e professores, o que contribui para a o desenvolvimento das pesquisas, além de proporcionar uma visão crítica sobre as fontes utilizadas na prática docente (GASQUE, 2012).

Portanto, o bibliotecário que conhece o potencial dos suportes no qual cotidianamente trabalha por intermédio dos processos de catalogação, classificação, indexação, resumos e demais atividades junto dos conhecimentos sobre o campo da memória social, podem ser grandes consultores na elaboração e organização de disciplinas que contemplem o uso de suportes e metodologias de pesquisa interdisciplinares ou que pelo menos apresentam questões inerentes ao campo da Memória Social como propulsora de várias questões cientificas.

Todavia, vale lembrar que a inserção do bibliotecário é difícil, "pois nem sempre as escolas percebem-no como colegas engajados no processo educacional" (FARIAS; VITORINO, 2009, p. 12). Muitas das vezes, para quebrar esta lacuna existente entre os atores de uma instituição de ensino, é necessário que aja a pró-atividade do bibliotecário de forma a mobilizar que os professores e alunos atuem em conjunto no desenvolvimento das atividades pedagógicas, com o intuito de gerar competências e qualidade nos processos de ensino e uso das ferramentas de pesquisa, seja os as fontes tridimensionais como os monumentos trabalhados ou demais suportes (textuais, iconográficos, audiovisuais e afins).

Esta preocupação pedagógica com o uso dos monumentos permite novos olhares para a pesquisa. Os monumentos citados, podem ser vistos como fonte de informação potencial quanto as questões políticas e históricas do país e não somente como um monumento que evoca a memória dos mortos da Segunda Guerra Mundial ou que homenageia um compositor como Ary Barroso. Os monumentos podem ser aproveitados de um modo mais crítico, criativo, possibilitando indagações e respostas quanto a questões mais profundas da história como: quem lutou pela recuperação dos corpos na Campanha da Itália para trazê-los ao atual monumento dedicado aos "pracinhas", investigar os artistas que planejaram o monumento e quais as escolhas que motivaram a construção do monumento tal como ele se apresenta, a participação política de Ary Barroso, os conflitos que o compositor enfrentou na política, com quem e o que motivou suas decisões em vida. Em resumo, os monumentos entendidos como um 'suporte de memórias', também podem ser utilizados como fonte de informação de múltiplas formas e por diversas áreas do conhecimento.

\section{Considerações}

Devido a complexidade de se trabalhar com fontes em formato tridimensional, exemplificado no estudo pelos monumentos escultóricos, pretende não concluir a questão, e sim evocar mais indagações. Algumas dificuldades foram apresentadas como a complexidade de se trabalhar com fontes que lidam de forma muito densa com as questões da memória, devido a sua dinamicidade, a dupla existência de memórias que apresentam-se como "oficiais" em detrimento das memórias ocultas, veladas e subterrâneas, o que traz a percepção de que há uma política de memória a edificar cada monumento, seja escultórico ou encontrado em outros formatos, além de evidencia uma dinamicidade, quanto aos olhares que podemos depreender sobre estes suportes ao utilizarmos como fonte de pesquisa. 
Além disso, temos a dificuldade do professor e do aluno, ao trabalhar com fontes que, além de serem de uso singular em salas de aula, implicam num processo pedagógico interdisciplinar, pois quando aplica-se um modelo pedagógico que utiliza-se das memórias incrustadas, visíveis ou não, nos monumentos, temos a incitação a mudanças no modelo unidimensional de ensino aplicado pelo docente (e habitualmente aceito pelos discentes) para o modelo interdisciplinar, complexo, crítico e dinâmico.

Por último, ainda temos o ator bibliotecário, que pode contribuir no processo educacional, tanto no que diz respeito ao uso pedagógico dos monumentos quanto no auxilio do processo didático propriamente dito (elaboração de disciplinas, pesquisas) e a própria competência informacional, no qual o bibliotecário, junto do professor e aluno, se inserem na cultura do aprender a aprender. Acredita-se que há uma carência sobre o uso pedagógico dos monumentos, principalmente os disponíveis em formato tridimensional, além de considerarmos essencial a mudança de cultura, no que diz respeito à inclusão do profissional bibliotecário no processo educacional.

\section{Referências}

ALVES, Claudia. O educador e sua relação com o passado. Educação em Revista, Belo Horizonte, v. 28, n. 3, p. 205-215, set. 2012.

ASSMANN, Aleida. Espaços da recordação: formas e transformações da memória cultural. Campinas, SP: Unicamp, 2011.

BARROSO, Ary. AryBarroso [página eletrônica]. Disponível em: 〈http://arybarroso.com.br/index.php?language=pt_BR>. Acesso em: 24 jun. 2014.

BENJAMIN, Walter. O narrador: considerações sobre Nikolai Leskov. In:

Magia e técnica, arte e política: ensaios Sobre Literatura e História da Cultura. São Paulo: Brasiliense, 2012.v. 1.

CHOAY, Françoise. A alegoria do patrimônio. 4. ed. São Paulo: Estação Liberdade; UNESP, 2006.

FARIAS, Christianne Martins; VITORINO, Elizete Vieira. Competência informacional e dimensões da competência do bibliotecário no contexto escolar. Perspectivas em Ciência da Informação. V. 14, n. 2, p. 2-16, mai./ago. 2009.

GASQUE, Kelley Cristine Gonçalves Dias. Práticas de pesquisa no contexto educacional. In: _ Letramento informacional: pesquisa, reflexão e aprendizagem. Brasília, DF: Faculdade de Ciência da Informação; Universidade de Brasília, 2012. P. 175

GONÇALVES, José Reginaldo Santos. A retórica da perda: os discursos do patrimônio cultural no Brasil. Rio de Janeiro: UFRJ, 2002.

GONDAR, Jô. Quatro proposições sobre memória social? In: GONDAR, Jô; DODEBEI, Vera (Org.). O que é memória social? Rio de Janeiro: Contra Capa, 2005.

HIRSCH, Marianne. The generation of postmemory: writing and visual culture after the holocaust. Nova York: Columbia University, 2012.

HUYSSEN, Andreas. Seduzidos pela memória: arquitetura, monumentos, mídia. 2. ed. Rio de Janeiro: Aeroplano, 2004.

LE GOFF, Jacques. História e memória. 6. ed. Campinas, SP: Unicamp, 2012.

MICHAELIS. Moderno dicionário de português online. São Paulo: Melhoramentos, 2014. Disponível em: <http://michaelis.uol.com.br/moderno/

Português/index.php?lingua=portugues-portugues \&palavra=pedagogia $>$. Acesso em: 24 jun. 2014. 
MONUMENTO NACIONAL AOS MORTOS DA SEGUNDA GUERRA MUNDIAL. MNMSGM [página eletrônica]. Rio de Janeiro, 1960. Disponível em: <http://www.mnmsgm.ensino.eb.br/MNMSGM.htm>. Acesso em: 24 jun. 2014.

NORA, Pierre. Entre memória e história: a problemática dos lugares. Projeto história, São Paulo, n. 10, p. 7-28, dez. 1993.

MORAES, Nilson Alves. Memória Social: Solidariedade Orgânica e disputas de sentido. In: DODEBEI, Vera; GONDAR, Jô (Org.) O que é Memória Social? Rio de Janeiro: Contracapa, 2005.

MOURA, Lisandro Lucas de Lima. Imagem e conhecimento: o uso de recursos didáticos visuais nas aulas de Sociologia. Cadernos de Pesquisa Interdisciplinar em Ciências Humanas, Florianópolis, SC, v. 12, n. 100, p. 159-182, jan./jul. 2011.

NORA, Pierre. Entre a memória e a história: a problemática dos lugares. Projeto história, n. 10, p. 7-28, dez. 1993.

PIRES, Eloiza Gurgel. Educação, narrativa e experiência. Cadernos de Pesquisa Interdisciplinar em Ciências Humanas, Florianópolis, SC, v. 15, n. 106, p. 5-26, jan./jun. 2014.

POLLAK, Michael. Memória e identidade social. Estudos Históricos. Rio de Janeiro, v.5, n.10, p. 200-212, 1992.

RIBEIRO, Leila Beatriz; OLIVEIRA, Carmen Irene Correia; WILKE, Valéria Cristina Lopes. Memória, informação, utopia e ficção-científica: construindo o conceito de memória do futuro. Cadernos de Pesquisa Interdisciplinar em Ciências Humanas, Florianópolis, SC, v. 11, n. 98, p. 146-177, jan./jun. 2010.

RIEGL, Alois. O culto moderno dos monumentos: a sua essência e a sua origem. 1. ed. São Paulo: Perspectiva, 2014.

SARLO, Beatriz. Tempo passado: cultura da memória e guinada subjetiva. São Paulo: Companhia das Letras; Belo Horizonte: UFMG, 2007.

SILVA, Wagner Rodrigues. Construção da interdisciplinaridade no espaço complexo de ensino e pesquisa. Cadernos de pesquisa, v. 41, n. 143, p. 582-605, mai./ago. 2011.

VARELA, Ainda. Informação e construção da cidadania. Brasília: Thesaurus, 2007 YOUNG, James. At memory's edge. Connecticut: Yale University, 2002. 